\title{
Knowledge and perception about stroke among an Australian urban population Sung Sug Yoon ${ }^{*}$, Richard F Heller ${ }^{2}$, Christopher Levi 3 and John Wiggers 4
}

Address: ${ }^{1}$ Centre For Clinical Epidemiology and Biostatistics (CCEB), Faculty of Medicine and Health Sciences, The University of Newcastle, New South Wales 2308, Australia, ${ }^{2}$ Public Health School of Epidemiology and Health Sciences Medical School, The University of Manchester, Oxford Road, Manchester M13 9PT United Kingdom, 3Department of Neurology, John Hunter Hospital, Locked Bag 1 New Lambton, Newcastle, NSW 2287 Australia and 4Hunter Centre for Health Advancement Faculty of Medicine and Health Sciences, The University of Newcastle, New South Wales 2308, Australia

E-mail: Sung Sug Yoon* - sungsyoon@yahoo.com; Richard F Heller - dick.heller@man.ac.uk; Christopher Levi - clevi@doh.health.nsw.gov.au; John Wiggers - john.wiggers@hunter.health.nsw.gov.au

*Corresponding author

\begin{abstract}
Background: The aim of the study was to measure knowledge about the symptoms, prevalence and natural history of stroke; the level of concern about having a stroke; understanding of the possibilities for preventing stroke, and the relationship between age, sex, country of origin, educational level, income, self-reported risk factors, and the above factors.
\end{abstract}

Methods: A random sample of households was selected from an electronic telephone directory in Newcastle and Lake Macquarie area of New South Wales, Australia, between 10 September and 13 October 1999. Within each household the person who was between 18 and 80 years of age and who had the next birthday was eligible to participate in the study ( 1325 households were eligible). The response rate was $62 \%$.

Results: The most common symptoms of stroke listed by respondents were "Sudden difficulty of speaking, understanding or reading" identified by $60.1 \%$ of the respondents, and "paralysis on one side of body" identified by $42.0 \%$ of the respondents. The level of knowledge of the prevalence of a stroke, full recovery after the stroke, and death from stroke was low and generally overestimated. $69.9 \%$ of the respondents considered strokes as being either moderately or totally preventable. There were few predictors of knowledge.

Conclusion: The study suggests that educational strategies may be required to improve knowledge about a wide range of issues concerning stroke in the community, as a prelude to developing preventive programmes.

\section{Background}

Stroke remains a leading cause of death, long-term disability, and health care expenditure, but opportunities ex- ist for reducing its cost to the community [1]. Recent advances in the treatment of acute ischemic stroke offer hope in reducing its devastating effects [2,3]. Primary 
prevention is also an important approach to substantially reducing the prevalence, recurrence, disability, and mortality of stroke [4-7].

Previous studies have shown that the knowledge of stroke among patients and in the community is poor. Pancioli and colleagues, [8] in a population based survey, found that $57 \%$ of respondents identified at least one of five established warning signs of stroke, $28 \%$ correctly listed two or more, and only $8 \%$ correctly identified three established warning signs of stroke. Our previous study [9] showed that only $73.4 \%$ of respondents from a random population sample identified the brain as the organ affected by stroke. While $76 \%$ of the respondents could list at least one risk factor for stroke, only $50 \%$ could identify one of the warning signs for stroke, $26 \%$ could correctly list two, and only $9 \%$ of respondents could correctly identify three or more warning signs.

There have been considerable efforts to increase knowledge about stroke and early presentation at the hospital when stroke symptoms occur. Alberts et al.[10] reported a highly significant improvement in presentation times for patients with cerebral infarction after the implementation of a community education program that used a multimedia approach. Before the program, $37 \%$ of patients with cerebral infarction presented to either a hospital or were referred from a general practitioner within 24 hours. After the program, the proportion of patients rose to $86 \%$. Stem et al.[11] also reported 10.9\% increase in stroke awareness and knowledge between the pre-education group and the post-education group in their community education programs.

Adequate planning of community interventions to prevent people from having their first stroke and to present at the hospital early after stroke symptoms occur will require a comprehensive multidisciplinary strategy. In the past, however, most researchers have focused on identifying the poor level of knowledge about stroke risk factors, symptoms, and treatment in hospital patients and in the general population, and there are no published data on the understanding of perceptions and beliefs about stroke in the community. This information is also a good resource for developing a public education program to reduce the occurrence of stroke and appropriate responses to the stroke symptoms.

This study aimed to measure in a random sample of the population:

- knowledge about stroke symptoms, prevalence, and natural history

- level of concern about having a stroke
- understanding of the possibilities for stroke prevention

- the relationship between age, sex, country of origin, educational level, income, self-reported risk factor, and the above factors.

\section{Methods}

Sample and setting

A random sample of 1773 households in Newcastle and Lake Macquarie, Australia, a regional city of approximately 250,000 people was randomly selected from an electronic telephone directory between 10 September and 13 October 1999. Within each household the person who was between 18 and 80 years of age and who had the next birthday was eligible to participate in the study.

\section{Procedure}

One week after mailing an information letter, a trained telephone interviewer contacted each selected household to conduct a telephone interview. If the eligible household member was not available to complete the interview, arrangements were made to call back at a later time. Three attempts were made to contact each eligible household member during the survey period.

\section{Measurement}

A literature review of previous studies concerning the chance of having a stroke and the knowledge of stroke symptoms, prevalence, mortality, and full recovery identified potential items for the survey instrument $[6,7,12-$ 15]. From this review a draft instrument was developed that addressed the knowledge of stroke symptoms, prevalence, mortality and full recovery. The final survey instrument contained 22 items divided into 3 sections:

- Knowledge and perception about stroke. These items addressed knowledge and perception regarding stroke symptoms, prevalence, mortality, and full recovery. Response options for each of these items were closed-ended questions.

- Respondents' demographic details (age, gender, marital status, country of origin, education, income),

- Prevalence of self-reported risk factors for stroke among the respondents (high blood pressure, angina, heart attack, previous stroke, diabetes, high cholesterol, smoking, and family history of stroke).

This study was approved by the Newcastle University and Hunter Area Research Ethics Committees.

\section{Statistical Analysis}

Descriptive and comparative statistical analyses were performed using the statistical program SAS version 
Table I: Demographic characteristics of the respondents $(n=$ 822)

\begin{tabular}{|c|c|}
\hline Age $($ mean $\pm S D)$ & $48.9 \pm 16.1$ \\
\hline \multicolumn{2}{|l|}{ Sex $>$} \\
\hline Male & 335 (48.0\%) \\
\hline Female & $487(52.0 \%)$ \\
\hline \multicolumn{2}{|l|}{ Country of origin } \\
\hline Australia & $715(87.0 \%)$ \\
\hline Overseas & 70 (I3.0\%) \\
\hline \multicolumn{2}{|l|}{ Education } \\
\hline Primary & $19(2.3 \%)$ \\
\hline Secondary & $514(62.6 \%)$ \\
\hline Tertiary & 279 (33.9\%) \\
\hline \multicolumn{2}{|l|}{ Income $(A \$)$} \\
\hline Less than $\$ 20,000$ & $252(30.7 \%)$ \\
\hline$\$ 20,000$ to $\$ 39,999$ & $189(24.8 \%)$ \\
\hline$\$ 40,000$ to $\$ 59,999$ & $142(15.3 \%)$ \\
\hline More than $\$ 60,000$ & $132(12.1 \%)$ \\
\hline Don't wish to answer & $107(13.0 \%)$ \\
\hline
\end{tabular}

6.12. Chi-squared tests were used to assess the relationships between components of stroke-related knowledge, demographic characteristics and self-reported risk factors. The effects of demographics and the presence of risk factors on the participants' knowledge of stroke were evaluated separately using logistic regression analyses. For each model, response options for the dependent variable were categorised as either 'know' or 'do not know'. $\mathrm{P}$-values from Wald statistics were used to assess the significance of predictor variables. Missing data were excluded. Two-tailed significance tests were used, and a probability value of less than 0.05 was considered statistically significant in both univariate and multivariate analyses.

\section{Results \\ Sample}

A total of 1773 telephone calls were made and of those, 1325 households were eligible. The remainder of the calls were ineligible (due to fax number, business phone number, disconnected, or no answer). A total of 822 participants completed the questionnaire giving a response rate of $62 \%$. Demographic characteristics of the respondents are presented in Table 1. Respondents were asked whether they had been told by health care professionals that they had a risk factor for stroke. Of the respondents,
Table 2: Respondent's knowledge of stroke symptoms $(n=822)$

\begin{tabular}{|c|c|}
\hline Responses & $\mathbf{N}(\%)$ \\
\hline $\begin{array}{l}\text { Sudden difficulty of speaking, understanding } \\
\text { or reading }\end{array}$ & $494(60.1 \%)$ \\
\hline \multicolumn{2}{|l|}{ Paralysis } \\
\hline any part of body & $229(36.4 \%)$ \\
\hline one side of body & $393(42.0 \%)$ \\
\hline $\begin{array}{l}\text { Blurred or double vision, loss of vision in an } \\
\text { eye or both }\end{array}$ & $243(29.6 \%)$ \\
\hline Incoordination or imbalance & $243(29.6 \%)$ \\
\hline Loss of memory & $125(15.2 \%)$ \\
\hline Brain malfunction & $76(9.0 \%)$ \\
\hline \multicolumn{2}{|l|}{ Numbness, tingling sensation, dead sensation } \\
\hline any part of body & $55(6.7 \%)$ \\
\hline one side of body & $63(7.7 \%)$ \\
\hline \multicolumn{2}{|l|}{ Weakness } \\
\hline any part of body & $53(6.4 \%)$ \\
\hline one side of body & $74(5.1 \%)$ \\
\hline Difficulty in swallowing & $33(4.0 \%)$ \\
\hline Dizziness (vertigo) & $24(2.9 \%)$ \\
\hline Headache / migraine & $20(2.4 \%)$ \\
\hline Chest pain, chest tightness, or murmur & $12(1.5 \%)$ \\
\hline Don't know & $54(6.5 \%)$ \\
\hline
\end{tabular}

258 (31.4\%) reported a high blood pressure (hypertension), 48 (5.8\%) diabetes, 24 (2.9\%) a previous history of stroke, $35(4.3 \%)$ angina, 206 (25.1\%) a high blood cholesterol, 180 (21.9\%) current smokers, and $356(43.3 \%)$ a family history of stroke.

\section{Knowledge of stroke symptoms}

Table 2 shows that the most common symptoms of stroke listed by respondents were "Sudden difficulty of speaking, understanding or reading" identified by 494 respondents (60.1\%), and "paralysis on one side of body" identified by 393 respondents (42.0\%). Six hundred and ninety four $(85.5 \%)$ respondents correctly listed at least one stroke symptom, 489 (60.2\%) correctly listed 2 symptoms, and $253(31.1 \%)$ correctly listed 3 or more symptoms of stroke. In the final logistic regression model, only higher educational level was a significant predictor of knowledge of stroke symptoms ( $\mathrm{p}=0.006, \mathrm{OR} ; 1.3$, 95\%CI; 0.67-0.93). No statistically significant interactions were found between demographic factors and selfreported risk factors or the knowledge of stroke symptoms.

\section{Knowledge of stroke prevalence, full recovery, mortality}

The level of knowledge of the prevalence of stroke in the community, the chance of full recovery after a stroke, and death from a stroke was generally low (Table 3). To the question "out of 100 Australians, how many do you 
Table 3: Respondents perception about the likelihood of developing a stroke, full recovery, and death after the stroke.

Response categories to question on likelihood (persons / 100)

\begin{tabular}{lccccc}
\hline & Australia rate (persons / 100)* & $0-10$ & $11-30$ & $31-50$ & $51-100$ \\
\hline & 1 & $20.7 \%$ & $30.6 \%$ & $29.2 \%$ & $19.5 \%$ \\
Developing a stroke $(n=729)$ & 33 & $22.9 \%$ & $19.6 \%$ & $34.2 \%$ & $23.4 \%$ \\
Full recovery after the stroke $(\mathrm{n}=731)$ & 9 & $26.7 \%$ & $40.8 \%$ & $23.4 \%$ & $9.2 \%$ \\
Death from the stroke $(\mathrm{n}=719)$ & & & & \\
\hline
\end{tabular}

*: Australian Institute of Health and Welfare (1999).

think will have a stroke in their life?" only a few respondents $(20.7 \%)$ were within $10 \%$ of the correct Australian rate. [16] Approximately half of the respondents over-estimated the prevalence of stroke in Australia by at least $50 \%$. The level of knowledge of stroke prevalence in this study is lower than similar study of telephone survey regarding knowledge of breast cancer in Australian women. This study showed that that one-third of respondents were able to make an approximately correct estimate of the incidence of breast cancer [17]. In the univariate analysis respondents with higher educational level ( $\mathrm{p}=$ $\mathrm{O} .001)$ and males $(\mathrm{P}=0.02)$ were more likely to estimate the likelihood of stroke within $10 \%$ of the correct answer.

When asked: "out of 100 Australians who have had a stroke, how many of them do you think will die as a result of stroke?" Approximately one third of respondents were within $10 \%$ of the Australian rate [16]. More than a half of the respondents over-estimated the risk of death after having a stroke. In the univariate analysis, respondents who had completed tertiary education were more likely to estimate within $10 \%$ of the correct answer than those who had not completed tertiary education $(p=0.004)$. Respondents with a history of high blood pressure were more likely to over-estimate the risk of death after a stroke than those without $(\mathrm{p}=0.003)$. However, in the final logistic regression model, there was no association between demographic factors or self-reported risk factors and knowledge of stroke prevalence and mortality in Australia.

The beliefs of respondents about the likelihood of having another stroke after the first stroke varied widely. 72 respondents (8.8\%) rated the likelihood the same as for a person who has not had a stroke, 399 respondents (48.5\%) rated the likelihood at 2 to 3 times, and 281 respondents (34.2\%) at more than 4 times more likely. Sixty-seven $(8.2 \%)$ respondents considered strokes as not preventable at all, $125(15.2 \%)$ respondents as slightly preventable, 506 (61.6\%) respondents as moderately preventable, $68(8.3 \%)$ respondents as totally preventable, while $56(6.8 \%)$ respondents did not know. Younger respondents (aged 18-39, $\mathrm{p}=0.001$ ) and those who had completed tertiary education $(p=0.04)$ estimated more correctly than those aged over 40 years and those who had not completed tertiary education.

\section{Concern about the possibility of having a stroke}

When asked about the chance of having a stroke during their lifetime ("What do you think are your chances of having a stroke in your life time?"), 651 respondents (91.1\%) reported no or only a low chance of their developing a stroke. Twenty-two respondents (3.1\%) reported a high lifetime chance of developing a stroke. More men reported moderate or high chances than did women ( $\mathrm{p}=$ 0.04). Respondents in each of these groups were more likely to indicate a low lifetime risk of stroke: Older Age (aged 60-80; $\mathrm{p}=0.001$ ). Lower Educational (completed primary school; $\mathrm{p}=0.001)$, and Born Overseas $(\mathrm{p}=$ o.01). Respondents who had been told by a health care professional that they have high blood pressure $(\mathrm{p}=$ $0.008)$, heart disease $(p=0.03)$, or previous stroke history ( $\mathrm{p}<0.001)$, and having a family history of stroke (first \& second degree relatives; $p=0.001$ ), were all more likely to think they had high chance of having a stroke in their lifetime than were respondents in other groups.

Table 4: Concern about the possibility of developing a stroke $(n=$ 822)

\begin{tabular}{ll}
\hline Frequency & $\mathbf{N}(\%)$ \\
\hline & \\
Never & $599(68.0 \%)$ \\
Occasionally & $164(19.9 \%)$ \\
Sometimes & $52(6.3 \%)$ \\
Always & $35(4.2 \%)$ \\
Don't know & $12(1.5 \%)$
\end{tabular}


To the question "In the last 12 months have you been at all concerned about the possibility that you might have a stroke?", more than half of respondents reported that they had not been concerned about their chance of having a stroke during the previous 12 months (Table 4). Younger respondents were more likely than older respondents to report that they were 'never' concerned about having a stroke in the last 12 months $(\mathrm{p}=0.003)$. Respondents who had been told by a health care professional that they had high blood pressure $(\mathrm{p}=0.001)$, diabetes $(p=0.004)$, or a high cholesterol level $(p<0.001)$ were more concerned about having a stroke than those who had not been so told. Respondents born in Australia were more likely to express concern about stroke than those born overseas ( $p=0.03$ ). Respondents with previous history of stroke $(\mathrm{p}<0.001)$ or family history of stroke $(\mathrm{p}=0.001)$ had experienced concern more often during the previous 12 months than did those without either personal or family stroke history.

\section{Discussion}

This community-based study demonstrates aspects of public knowledge and perception about stroke. Of 822 respondents, 694 (85.5\%) were able to name at least one established stroke symptom. Respondents, in general, overestimated both stroke prevalence in Australia and the chance of full recovery after the stroke. Respondents generally considered the possibility of their having a stroke during their life as being not a matter of serious concern. In a multiple logistic regression model, only one group - those with a higher level education - had better knowledge of established stroke symptoms.

"Sudden difficulty of speaking, understanding or reading" was listed as the most common stroke symptom and more than $80 \%$ of respondents could list at least one established stroke symptom. In a hospital-based prospective study Kothari et al.[18] reported that unilateral weakness and numbness were the stroke symptoms most frequently noted by patients. Two-fifths of patients could not identify a single symptom of stroke. In the final logistic regression model, there was no significant association between self-reported stroke risk factors and knowledge of stroke symptoms. These results suggest that respondents who recognise in themselves an established stroke symptom still need to be educated by their doctor or through community educational programs.

Although those with stroke risk factors (high blood pressure, diabetes, heart disease, previous stroke history etc) correctly identified themselves as having a higher risk of stroke [12], the older respondents incorrectly identified themselves as having a lower risk of stroke. Providing the older members of the community with information about how to recognise stroke symptoms and how to ac- cess emergency system in the event of their experiencing stroke symptoms may be beneficial. Furthermore, it would seem advisable to evaluate the role of denial in health behaviour and to develop and test educational strategies to address this denial.

Prevention remains the most important approach to substantially reducing the prevalence, recurrence, disability, and mortality of stroke. Respondents showed a positive attitude to the possibility of stroke prevention. Gorelick[19] discussed reduction of stroke risk. In his review, lifelong behaviours controlling risk factors are best achieved during pre-adolescence or adolescence. Randall et al., and Kingsley et al. [20,21] emphasised the necessity of finding methods to educate and motivate the population to reduce risk factors, and the importance of educating patients about their risk factors after examining them in the primary care setting.

A comparatively low proportion of respondents expressed concern about their lifetime chance of having a stroke. Respondents informed by health care professionals that they had a stroke risk factor were more concerned about the possibility of having a stroke than those who had not been told. However, those with stroke risk factors had no better knowledge of stroke symptoms than those without risk factors. Even if overall attitude towards stroke prevention was optimistic in this study, this result may indicate that some deny risk and that some accept and at the same time practically ignore their own personal risks. Research that could determine educational methods of bridging the knowledge-behaviour gap might focus on people's apparent reluctance to change life style towards prevention of stroke and on ways of bringing people to accept calling the emergency medical system as a natural and proper response when they experience stroke symptoms.

Since this is the first study of its kind in Australia, the results might not be generalisable across Australia, (or to other countries).

\section{Conclusions}

In conclusion, the knowledge of stroke symptoms in general was high, but the knowledge about stroke prevalence, mortality, and recovery after the stroke was poor. The lifetime chance of having a stroke was in general underestimated. This study suggests that education strategies may be required to improve knowledge about a wide range of issues concerning stroke in the community, as a prelude to developing preventive programmes.

\section{Competing interests}

None declared 


\section{Acknowledgements}

This research was supported by the John Hunter Hospital Research Committee, Newcastle, Australia.

\section{References}

I. National Stroke Association: Stroke/Brain attack briefing. Colo: Postgraduate institute for medicine. Englewood I 996I-34

2. The National Institute of Neurological Disorders and Stroke rt-PA stroke study group: Tissue plasminogen activator for acute ischemic stroke. $N$ Engl J Med 1995, 333(24): I58|- I 587

3. Stroke Unit Trialists' Collaboration: Collaborative systematic review of the randomized trials of organized inpatient (stroke unit) care after stroke. $B M / 1997,3$ I 4:I I5 I-I I59

4. Gorelick PB, Schneck M, Berglund LF, Feinberg W, Goldstone ]: Status of lipids as a risk factor for stroke. Neuroepidemiology 1997, 16(3): $107-115$

5. Iso H, Jr Jacobs DR, Wentworth D, Neaton JD, Cohen JD: Serum cholesterol levels and six-year mortality from stroke in $\mathbf{3 5 0 , 9 7 7}$ men screened for the Multiple risk Factor Intervention Trial. N Engl J Med 1989, 320:904-910

6. MacMahon S: Blood pressure and the prevention of stroke. J Hypertens Suppl 1996, I4(6):S39-S46

7. Wolf PA, D'Agostino RB, Kannel WB, Bonita R, Belanger AJ: Cigarette smoking as a risk factor for stroke: The Framingham Study. JAMA 1988, 259(7): 1025-1029

8. Pancioli AM, Broderick J, Kothari R, Brott T, Tuchfarber A, Miller R, Khoury J, Jauch E: Public perception of stroke warning signs and knowledge of potential risk factors. JAMA 1998, 279( I 6): I 288-1292

9. Yoon SS, Heller RF, Levi C, Wiggers ], Fitzgerald PE: Knowledge of stroke risk factors, warning symptoms, and treatment among an Australian urban population. Stroke 2001, 32:19261930

10. Alberts MJ, Perry A, Dawson DV, Bertels C: Effects of public and professional education on reducing the delay in presentation and referral of stroke patients. Stroke 1992, 23(3):352-356

II. Stem EB, Berman ME, Thomas JJ, Klassen AC: Community education for stroke awareness an efficacy study. Stroke 1999, 30:720-723

12. American Heart Association: Stroke risk factors [on-line]. October II, 1999 [americanheart.org/Heart_and_Stroke_A_Z_Guide/ asa.html]

13. Dracup K, Moser DK, Eisenverg M, Meischke H, Alonzo AA, Braslow A: Causes of delay in seeking treatment for heart attack symptoms. Soc Sci Med I 995, 40(3):379-392

14. Ferro JM, Melo TP, Oilveira V, Crespo M, Canhão P, Pinto An: An analysis of the admission delay of acute stroke. Cerebrovasc Dis 1994, 4:72-75

15. Meischke H, Ho MT, Eisenberg MS, Schaeffer SM, Larsen M: Reasons patients with chest pain delay or do not call 9 I I. Annals of emergency medicine 1995, 25(2):193-197

16. Australian Institute of Health and welfare: Heart Stroke and Vascular disease-Australian Facts. December 16, 1999 [http:// www.aihw.gov.au/]

17. Paul C, Barratt A, Redman S, Cockburn J, Lowe J: Knowledge and perceptions about breast cancer incidence, fatality and risk among Australian women. Australian \& New Zealand Journal of Public Health 1999, 23(4):396-400

18. Kothari R, Sauerbeck L, Jauch E, Broderick J, Brott T, Khoury J, Liu T: Patients' awareness of stroke signs, symptoms, and risk factors. Stroke 1997, 28(10): |87|-1875

19. Gorelick PB: Stroke prevention: windows of opportunity and failed expectations? A discussion of modifiable cardiovascular risk factors and a prevention proposal [editorial]. Neuroepidemiology 1997, 16(4): 163-73

20. Kingsley CM, Gupta SC: How to reduce the risk of coronary artery disease: teaching patients a healthy life-style. Postgrad Med 1992, 91:147-160

21. Randall OS, Retta TM, Ordor OE, Courtney BL: Can risk factor modification reduce cardiovascular morbidity and mortality in minority population?. Preventive Medicine 1996, 25:61-62
Publish with BioMed Central and every scientist can read your work free of charge

"BioMedcentral will be the most significant development for disseminating the results of biomedical research in our lifetime." Paul Nurse, Director-General, Imperial Cancer Research Fund

Publish with BMC and your research papers will be:

- available free of charge to the entire biomedical community

- peer reviewed and published immediately upon acceptance

- cited in PubMed and archived on PubMed Central

- yours - you keep the copyright 